WILDERNESS IMAGE

\title{
A Light in the Dark: The Discovery of Another Fluorescent Frog in the Costa Rican Rainforests
}

Pablo Deschepper, MSc; Bert Jonckheere, BS; Jasper Matthys, BS

From Ecology, Evolution and Biodiversity Conservation, University of Leuven, Leuven, Belgium (Mr Deschepper).

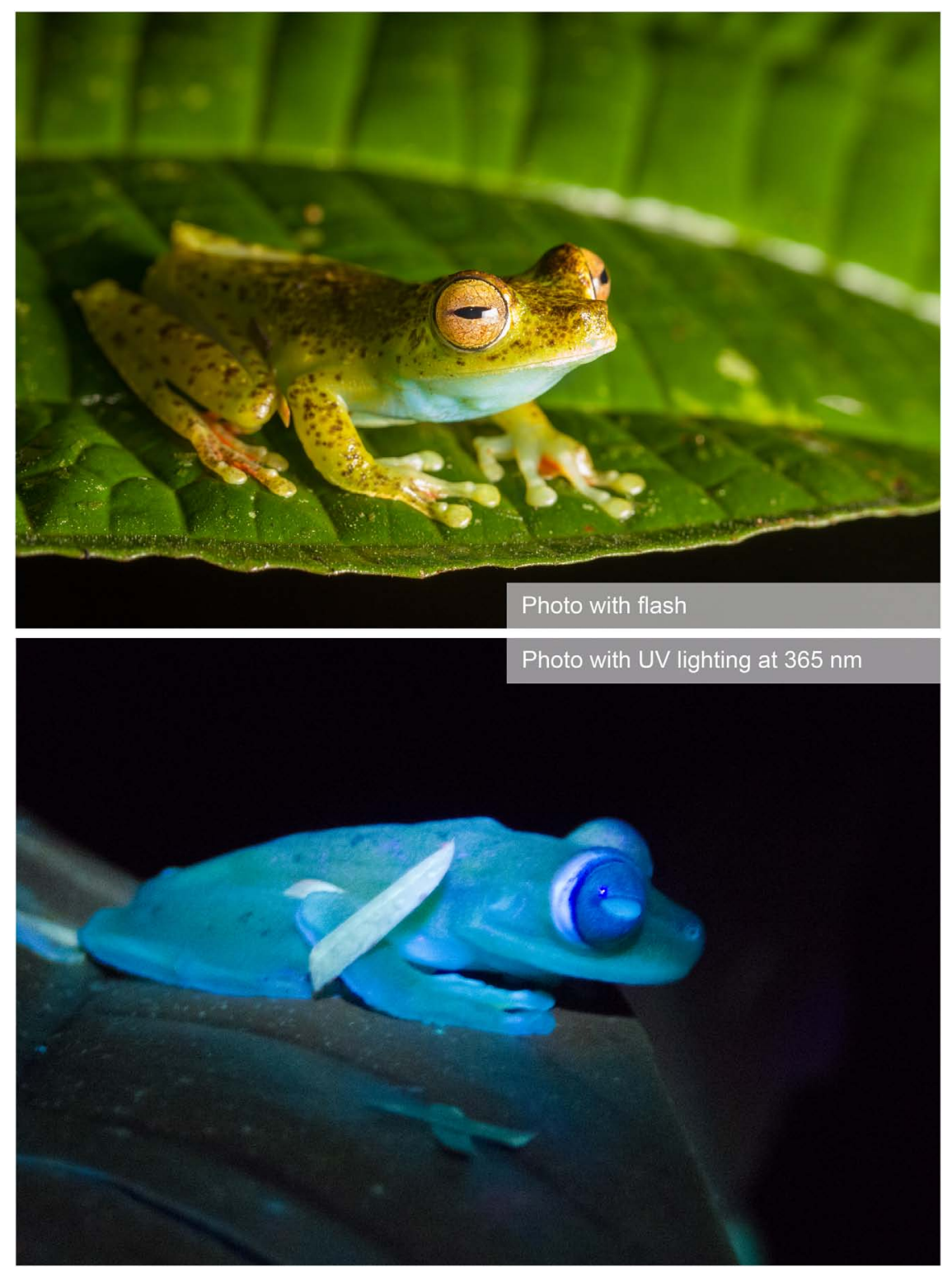


Fluorescence, or the re-emittance of longer wavelength light under shorter wavelength light, is a recurrent phenomenon in many animal species. Mounting evidence suggests that fluorescence is likely to be more ubiquitous than once thought. ${ }^{1}$ Fluorescence is thought to play a role in recognition of conspecifics and interspecific interaction. ${ }^{1-3}$ Recently it has been shown that the bony tubercules of quite a few chameleon species fluoresce under ultraviolet (UV) A light, which could be related to signaling cues between the sexes. ${ }^{1}$ Other species that fluoresce with excitation of UV or near UV light include many fish taxa, ${ }^{2}$ jumping spiders, ${ }^{3}$ birds, ${ }^{4}$ mantis shrimp, ${ }^{5}$ and at least 1 frog species, Hypsiboas punctatus. ${ }^{6}$

Equipped with a high quality UV light (Convoy S2+) and a digital single-lens reflex camera, we observed and photographed several individuals of another frog species that exhibit fluorescence when exposed to light with a peak wavelength of $365 \mathrm{~nm}$. Boana rufitelus is a close relative of $H_{\text {punctatus }^{6}}$ and can be found from southern Nicaragua into the northern part of Panama. We found the species on low, broad-leafed vegetation near small bodies of water at the edge of Braulio Carrillo National Park.

The close match between sensitivity of 2 retinal rods in low-light conditions in several frog species, especially Hyla cinerea, and the fluorescence emission spectra in $H$ punctatus suggest a role for fluorescence in identifying conspecifics at night. Taboada et al have estimated the contribution of the reflectance spectrum of fluorescence of $H$ punctatus to the total emerging light to range from $18.5 \pm 2.6 \%$ on a full moon night to $29.6 \pm 3.2 \%$ during twilight. ${ }^{7}$ It is likely that the way in which some nocturnal frogs see their environment renders emitted fluorescence more obvious to them than to the human eye.
Interestingly, some predators (birds) have vision that extends into the UV spectrum, in which fluorophores of some spiders fluoresce most intensely. ${ }^{7}$ This could have elaborate consequences concerning the selective pressures on some prey animals such as spiders and frogs. Further research could investigate whether predators of fluorescent frogs are able to exploit this "lighting up in the dark" feature with tailored receptor cells in their retina.

Unfortunately, many frog species are under increasing threat of extinction. Frogs have been discussed as a sentinel group for environmental degradation because they often are the first taxonomic group to disappear under increasing human impact.

Photograph by Pablo Deschepper, MSc.

\section{References}

1. Prötzel D, Heß M, Scherz MD, Schwager M, Padje AV, Glaw F. Widespread bone-based fluorescence in chameleons. Scientific Reports. 2018;8:698.

2. Sparks JS, Schelly RC, Smith WL, Davis MP, Tchernov D, Pieribone VA, et al. The covert world of fish biofluorescence: a phylogenetically widespread and phenotypically variable phenomenon. PLoS One. 2014;9:e83259.

3. Lim ML, Land MF, Li D. Sex-specific UV and fluorescence signals in jumping spiders. Science. 2007;315(5811):481.

4. Arnold KE, Owens IP, Marshall NJ. Fluorescent signaling in parrots. Science. 2002;295(5552):92.

5. Mazel C, Cronin T, Caldwell R, Marshall N. Fluorescent enhancement of signaling in a mantis shrimp. Science. 2004;303(5654):51

6. Taboada C, Brunetti AE, Pedron FN, Carnevale Neto F, Estrin DA, Bari SE, et al. Naturally occurring fluorescence in frogs. Proc Natl Acad Sci USA. 2017;114(14):3672-7.

7. Andrews K, Reed SM, Masta SE. Spiders fluoresce variably across many taxa. Biol Lett. 2007;3(3):265-7. 